ESTUDOS RBEP

\title{
O impacto da pobreza no Ideb: um estudo multinível
}

Natalia de Souza Duarte

\section{Resumo}

Objetiva investigar, por meio de análise de regressão multinível, o impacto da pobreza no Índice de Desenvolvimento da Educação Básica (Ideb) das escolas. Para tanto, foi considerado o percentual de beneficiários do Programa Bolsa Família nas instituições de ensino com Ideb 2009. Na composição do modelo matemático, foi utilizada a metodologia multinível e inseridas variáveis do nível da escola e do município. Depois de considerar o efeito das variáveis dos diferentes níveis, verificou-se um impacto de -0,42 no modelo 1 e -0,29 no modelo 2. Isso significa que a presença de alunos em situação de pobreza tem efeito negativo bastante considerável no Ideb da escola; custo-aluno, população e região também interferem nessa relação. Espera-se que os resultados deste estudo apoiem o enfrentamento da meritocracia e a defesa de mais recursos para a educação.

Palavras-chave: pobreza; custo-aluno; análise de regressão multinível; Ideb. 


\section{Abstract \\ The impact of poverty on Ideb: multilevel study}

The aim of this study is to investigate the impact of poverty on Ideb schools, using multilevel regression analysis. Therefore, the percentage of Bolsa Família's beneficiaries in schools with Ideb 2009 was considered. The mathematical model was composed by multilevel methodology as well as variables of school and county levels. After considering the effect of different levels of variables, there was an impact of -0.42 in model 1 and $-0.29 \mathrm{in}$ model 2. This means that the presence of students in poverty has a strongly negative effect on Ideb results. Public spending per student, population and region also interfere. It is hoped that the results of this study support the coping with meritocracy and the efforts to increase government investments in education.

Keywords: poverty; public spending; multilevel regression analysis; Ideb.

\section{Apresentação}

Esta pesquisa é integrante do projeto Política educacional e pobreza: estudo em escolas públicas que atendem a população em situação de pobreza, aprovado no âmbito do Edital no 34/2010 do Programa Observatório da Educação da Coordenação de Aperfeiçoamento de Pessoal de Nível Superior (Capes), com financiamento de despesas de custeio, capital e bolsas nos anos de 2011 e 2012. Tal projeto tem por objetivo estudar as manifestações da relação entre educação formal e população em situação de pobreza tanto no que se refere a resultados de proficiência e qualidade como na atuação das distintas esferas de governo, e no interior da própria escola, e é coordenado pela professora doutora Silvia Cristina Yannoulas. O programa é resultado da parceria entre a Capes, o Instituto Nacional de Estudos e Pesquisas Educacionais Anísio Teixeira (Inep) e a Secretaria de Educação Continuada, Alfabetização, Diversidade e Inclusão (Secadi) e foi instituído pelo Decreto Presidencial no 5.803/2006. Tem por finalidade fomentar, por meio de financiamento, redes de estudos e pesquisas em educação que utilizem a infraestrutura disponível das Instituições de Educação Superior (IES) e as bases de dados existentes no Inep, estimulando a produção acadêmica e a formação de recursos pós-graduados, em nível de mestrado e doutorado; além de fortalecer o diálogo entre a academia e gestores das políticas nacionais.

O projeto Política educacional e pobreza: estudo em escolas públicas que atendem a população em situação de pobreza tem por resultados esperados: 1) análise estatística da relação entre população em situação 
de pobreza no Índice de Desenvolvimento da Educação Básica (Ideb) das escolas públicas do Distrito Federal; 2) melhor compreensão das relações entre alunos, família, escolas e condição de pobreza; 3) taxionomia da produção científica sobre educação e pobreza; 4) melhor compreensão das políticas formuladas a partir de avaliações institucionais e de maximização de seus impactos na melhoria da educação; 5) melhor compreensão da relação da política educacional com a população em situação de pobreza; 6) realização de seminários locais e nacional; e 7) publicação de livro. Esta pesquisa se relaciona mais especificamente com o objetivo 5 .

\section{Introdução}

Para Villas Boas (2008), a avaliação precisa estar comprometida com a aprendizagem de alunos e professores, com o desenvolvimento da escola e com todo o processo de reorganização do trabalho pedagógico. Entretanto, a divulgação dos resultados do Ideb 2011 e a reação da mídia ${ }^{1}$ ante as disparidades encontradas entre as escolas públicas obrigam reconhecer que as avaliações nacionais e internacionais têm servido à hierarquização - de profissionais, escolas e sistemas de ensino. Sem avalizar o Ideb enquanto indicador capaz de medir eficientemente a qualidade da educação de uma escola, mas reconhecendo sua capacidade de visibilizar fragilidades - da política educacional -, defende-se neste artigo a sua interpretação como indicador de vulnerabilidades sociais que deve acionar apoio, ao tempo que pode enfrentar a lógica de responsabilização individual do fracasso escolar (Freitas, 2007).

Qualquer indicador de política social (e educação é uma política social) deve ser capaz de acionar programas e ações que apoiem as instituições que apresentam vulnerabilidades. Dessa forma, quando a hierarquização/responsabilização pelo Ideb cede ao suporte necessário para se assegurar aprendizagens a todos, a educação demuda-se de direito liberal individual para direito social inalienável - o direito à educação (acesso) precisa ser acompanhado do direito de aprender (sucesso). No entanto, a escola vem exercendo "pressão seletiva" sobre a população em situação de pobreza por meio da "ação dos mecanismos de atuação institucional sobre os diversos (e desiguais) grupos que ocupam a escola, promovendo-os, distinguindo-os e permitindo-lhes a ocupação de posições necessariamente desiguais nesse espaço profundamente marcado por hierarquias" (Peregrino, 2010, p. 134-135). Em outras palavras, a escola tem oferecido percursos diferenciados aos diversos grupos que a

${ }^{1}$ Ver, por exemplo, a matéria da frequentam, em especial, a partir da renda e classe social.

Há pelo menos 60 anos a sociologia da educação tem associado resultados educacionais a condições socioeconômicas dos alunos e a condições infraestruturais da educação. ${ }^{2}$ Para Andrade e Laros (2007, p. 34), "no processo avaliativo também se deve considerar que o desempenho dos avaliados precisa ser contextualizado. Isto é relevante uma vez que as desigualdades sociais têm implicações diretas sobre a educação".

${ }^{2}$ Ver Relatório Colemann de 1966 . 
Entretanto, a responsabilização recorrente pelo fracasso da escola em territórios de vulnerabilidade vem recaindo muito mais sobre os atores da política educacional (em especial sobre o professor) do que sobre as desigualdades gritantes e a precariedade recorrente das escolas públicas brasileiras (excetuando-se as federais).

O uso do Ideb como indicador da necessidade de maiores e novos aportes da política educacional pode vir a romper a lógica convencional da responsabilização (accountability) dos atores pelo mau resultado da atuação da política educacional. Essa nova perspectiva é acionada especialmente quando se visa aportar apoio maior justamente às escolas e aos sistemas educacionais que apresentaram os piores índices. Segundo o Plano de Desenvolvimento da Educação (PDE), houve uma priorização de sistemas e escolas que apresentaram os índices mais baixos, algo inverso ao convencionalmente praticado por alguns países, pois as escolas que apresentam os melhores resultados recebem mais recursos, o que aumentou a distância entre as que atendem a população em situação de pobreza e as que se situam em territórios mais favorecidos (Brasil. MEC, 2007). Entretanto, essa lógica ainda não foi incorporada de forma inequívoca, e a hierarquização acaba por acionar a responsabilização. Freitas (2007, p. 965) alerta para o fato de que

\begin{abstract}
as políticas de responsabilização unilaterais conduzirão à configuração de escolas para pobres e escolas para ricos, bem como alerta para o risco de que os sistemas de avaliação externa centralizados na Federação ocultam, em indicadores estatísticos como o Ideb, as dificuldades que as classes populares estão tendo para aprender no interior da escola, legitimando estratégias que somente conduzem ao adiamento da exclusão destas - apesar do discurso da transparência e responsabilidade.
\end{abstract}

É necessário reverter essa lógica sob pena de desqualificar, de forma irrecuperável, a dignidade dos docentes. A lógica necessária precisa se apoiar na política educacional, especialmente com mais recursos, por meio da elevação do custo-aluno. ${ }^{3}$ É sob essa orientação que este estudo busca enfrentar a perspectiva de responsabilização confirmando - mais uma vez - como a pobreza impacta o Ideb e como o financiamento pode moderar esse fato.

\section{Aproximação da teoria crítica da relação entre pobreza e fracasso escolar}

A resistência teórica à meritocracia busca desvelar que os resultados escolares dos alunos não são a combinação de esforço pessoal e imparcialidade da escola, e há vasta produção nacional e internacional nessa perspectiva. Para Henriques (2000, 2002), as classes populares têm percurso escolar diferenciado: fracasso escolar, baixa proficiência, reprovação, evasão e exclusão. Esse percurso apõe a essa população acesso menor ao ensino médio e difícil ao ensino superior.

\footnotetext{
${ }^{3}$ Custo-aluno é definido na Lei de Diretrizes e Bases (LDB), em seu artigo $4^{\circ}$, inciso IX, como "a variedade e quantidade mínimas, por aluno, de insumos indispensáveis ao desenvolvimento do processo de ensino-aprendizagem". Essa definição é complementada no art. 74, parágrafo único: $\mathrm{O}$ custo mínimo de que trata este artigo será calculado pela União ao final de cada ano, com validade para o ano subsequente, considerando variações regionais no custo dos insumos e as diversas modalidades de ensino."
} 
O francês Dubet (2004, p. 541) explica que "as sociedades democráticas escolheram convictamente o mérito como um princípio essencial de justiça: a escola é justa porque cada um pode obter sucesso nela em função de seu trabalho e de suas qualidades". Entretanto, "o mérito desempenha um papel apenas marginal para os filhos dos trabalhadores". Essa tese - com 30 anos de diferença - é a mesma dos franceses Bourdieu e Passeron (1973), que denunciaram a reprodutividade da escola ainda na década de 60. Para esses autores, o funcionamento da escola cumpre, simultaneamente, o papel de reprodução cultural e social, pois recria relações sociais e produtivas da sociedade capitalista.

Algumas pesquisas nacionais recentes vêm contribuindo para o entendimento da nova função da escola, pois a incorporação das camadas populares e em situação de pobreza exige refazer o modus operandi do estabelecimento de ensino. Com diferentes enfoques, Soares (2011), Guimarães-Iosif (2009), Algebaile (2009), Peregrino (2010) e Barbosa (2010) concordam que a incorporação da classe popular na escola veio acompanhada de desescolarização e desinstitucionalização desta.

Algebaile (2009) aponta que as funções de negociação e mediação que a escola passa a cumprir para o Estado, especialmente na relação com a pobreza, a impõem o gerenciamento de programas como saúde escolar, programas assistenciais de caráter compensatório, bolsa escola, bolsa família - o que exige novas funções em detrimento de aspectos fundamentais da educação. Essa sobreposição possibilita ao Estado dissimular suas ausências, mas sobrecarrega a escola com oferta de serviços muitas vezes simbólicos e sem efetividade na garantia de direitos. Guimarães-Iosif (2009) afirma que a baixa qualidade educacional das escolas públicas que atendem a população pouco favorecida contribui para o aprofundamento da pobreza e da desigualdade social, comprometendo a aprendizagem e a cidadania dos alunos e dos próprios professores.

Já Peregrino (2010) analisa a expansão degradada da escola e as formas de escolarização daí resultantes. A ampliação das funções escolares, a precariedade e desqualificação do atendimento escolar e a separação de seus usuários em função das desigualdades econômicas acabam por acionar mecanismos de diferentes modos de escolarização que ativam o "fracasso programado" na trajetória estudantil dos pobres. Barbosa (2010) examina fatores individuais e sociais como barreiras ao desempenho escolar, mas defende que as escolas, seus procedimentos administrativos e pedagógicos, o treinamento profissional e trabalho, a experiência docente e o estilo escolar têm efeitos que também atuam como variável explicativa do desempenho dos alunos, defendendo o resgate do pedagógico na instituição de ensino. Para a autora, professores e contexto da sala de aula podem, sim, superar os enfoques deterministas da educação.

$\mathrm{Na}$ mesma linha de visibilizar a correlação entre condições socioeconômicas desfavoráveis e fracasso escolar são os estudos que analisam as precariedades materiais das escolas que atendem as classes populares. O Instituto de Pesquisa Econômica Aplicada (2008, p. 21) afirma 
- na contramão da literatura internacional neoliberal sobre o tema - que "os insumos escolares são muito relevantes na definição dos resultados educacionais". O próprio Inep ressalta a importância de se considerar os equipamentos presentes nas escolas - assim como as desigualdades sociais -, pois estes têm implicações diretas sobre a educação (Brasil. Inep, 2001).

Partindo da perspectiva apresentada, defende-se aqui que visibilizar o impacto da pobreza no Ideb pode contribuir para o desenho de políticas, programas e ações que melhorem as condições de funcionamento da escola ao tempo que forcem mais recursos para a política educacional.

\section{Educação e fracasso escolar}

O acesso aos diversos níveis de ensino, mesmo que, mormente, ao nível fundamental, é grande conquista para as classes populares e inaugurou o ingresso dessa população em uma instituição que antes era elitista e limitada a uma minoria. Hoje, a escola pública brasileira atende ao universo da população em idade escolar e é realidade presente em todos os territórios nacionais. No entanto, é importante refletir sobre o fato de o sistema educacional brasileiro ter substituído a exclusão da escola pelo fracasso escolar para alguns segmentos da sociedade.

Neste estudo, o fracasso escolar foi analisado muito mais por suas manifestações - baixa proficiência, reprovação e distorção idade/série - do que por suas causas. Uma breve apresentação de dois autores nacionais referência na literatura sobre o tema pode ajudar na compreensão do porquê de o fracasso escolar recair, especialmente, sobre a população em situação de pobreza: são eles Patto (1990) e Freitas (2007).

Patto (1990) analisou as causas das desigualdades educacionais na sociedade brasileira associando contexto socioeconômico e político a preconceitos que prejudicam a trajetória escolar individual. Em virtude de a escola funcionar como instrumento de ascensão e de prestígio social, Patto examina o discurso, produzido pela psicologia, que justifica as dificuldades de aprendizagem com uma visão organicista das aptidões humanas, carregada de pressupostos racistas e elitistas. A causa do fracasso é então apontada como a inadequação da escola decorrente da representação negativa da capacidade intelectual dos alunos e da consequente desvalorização social da população em situação de pobreza. O funcionamento do sistema educacional é, congenitamente, gerador de obstáculos à realização de seus objetivos universais e democráticos, ideologizando por meio de discurso científico que naturaliza o fracasso aos olhos de todos os envolvidos no processo.

Freitas (2002) analisa o fracasso escolar como fruto de três fenômenos distintos: ocorre no interior da escola a conversão da exclusão objetiva em exclusão subjetiva por meio da organização do trabalho pedagógico realizado no e pelo estabelecimento escolar; também se aciona a avaliação informal para a criação de trilhas de progressão continuada diferenciadas; 
e, por fim, ocorre a desresponsabilização das instituições de ensino em relação à escolarização das camadas populares.

Os processos denunciados por esses autores ganharam contornos mais específicos a partir dos resultados dos sistemas de avaliação educacional, iniciado nos anos 90, que se consolidam com o Ideb. Criado para medir a qualidade da escola e das redes de ensino, o primeiro Ideb, em 2005, visibilizou sistemas de ensino com notas que variavam de 1,8 a 6,0 e escolas com notas que variavam de 0,7 a 8,5, em uma escala de 0 a 10. O Ideb de 2009 dos sistemas municipais variou de 0,5 a 8,2 e das escolas, de 0,8 a 9,0 (Brasil. MEC, 2007), ou seja, a discrepância aumentou, sendo que os baixos índices nos levam, justamente, aos territórios de maior risco e vulnerabilidade social. Essa recorrência instigou a realização desta pesquisa.

\section{Compartilhando a pesquisa}

Como dito na apresentação, este trabalho integra o projeto Política educacional e pobreza: estudo em escolas públicas que atendem a população em situação de pobreza. Assim, esta pesquisa objetivou contribuir com a perspectiva crítica do fracasso escolar investigando e visibilizando (mais uma vez) o impacto da pobreza no Ideb das escolas públicas. Para tanto, optou-se por estudo quantitativo, que permitisse uma aproximação estatística desse impacto, e multinível, um tipo de regressão multivariada que considera os níveis em que as variáveis estão inseridas para não ocorrer o "rebaixamento artificial" de variáveis de níveis diferentes em um único plano, ou seja, a regressão multinível considera a estrutura hierárquica dos dados (Laros; Marciano, 2008).

A hipótese formulada para este estudo foi de que a educação formal se relaciona com a população em situação de pobreza, consideravelmente, mediante o fracasso escolar e que, se fosse possível ponderar essa população em cada uma das escolas, se verificaria por meio de estudo regressivo multivariado multinível o impacto negativo da pobreza no Ideb. Há algum tempo o estudo multinível vem sendo a pesquisa estatística que reconhece a hierarquia na filiação dos dados. O exame da adequação deste estudo à modalidade multinível foi realizado a partir da comprovação das recomendações de Puente-Palacios e Laros (2009, p. 350), para os quais a principal exigência a ser cumprida do estudo multinível é a verificação do atendimento ao princípio teórico básico de que "a adoção de modelos de desenho multinível para a compreensão de um determinado fenômeno implica o reconhecimento da existência de elementos explicativos provenientes de diferentes níveis". Também é necessário o estabelecimento dos níveis a ser contemplado no modelo proposto, a definição das relações entre as variáveis inseridas no modelo e a confirmação da existência de relações de influência mútua entre as variáveis hierárquicas. 
A pobreza já foi percebida, descrita e analisada de múltiplas formas, inclusive em concepções mais individualistas e liberais às quais insurgem percepções mais críticas e imparciais que incitam, por sua vez, perspectivas prescritivas e juízos de valores. Fenômeno presente nos agrupamentos humanos desde o princípio dos tempos até os dias atuais, a pobreza é uma experiência humana e social que acompanha a existência do homem sobre a terra e se caracteriza por "situações de carência em que os indivíduos não conseguem manter um padrão mínimo de vida condizente com as referências socialmente estabelecidas em cada contexto histórico" (Henriques, 2000, p. 22).

Nesta pesquisa, a pobreza é compreendida como produto da relação contraditória fundamental entre capital e trabalho que ameaça à ação política de sujeitos em dadas circunstâncias e se caracteriza pelo não acesso ou acesso precário a renda, aos direitos, aos serviços sociais e ao trabalho formal e protegido. Não reduzindo a pobreza à renda, mas entendendo um critério objetivo para estabelecê-la em uma escola, utilizou-se como recorte de pobreza ser Beneficiário do Programa Bolsa Família (BPBF) com frequência escolar acompanhada pelo Ministério da Educação (MEC). Essa escolha também se deu em função de se assegurar a precisão necessária para o estudo. Muitos índices refletem indiretamente a situação de pobreza: Índice de Desenvolvimento Humano (IDH), Territórios da Cidadania, Coeficiente de Gini, Produto Interno Bruto (PIB) per capita, etc. Entretanto, em virtude da desigualdade constitutiva do Brasil (Souza, 2003), os cálculos que utilizam médias e ponderações acabam por invisibilizar a pobreza, distorcendo, distribuindo e mediando-a.

Para proceder ao estudo, o primeiro desafio consistiu em constituir um banco de dados que permitisse calcular o impacto da população em situação de pobreza no Ideb das escolas. O recorte válido para localização dessa população na escola e nos sistemas de ensino. A intenção metodológica da pesquisa exigia encontrar o número mais aproximado possível de "pobres" matriculados em cada escola do Brasil a fim de revelar as desigualdades de desempenho escolar. A opção objetiva adotada foi utilizar como recorte de pobreza ser BPBF.

Como a metodologia escolhida foi uma regressão multivariada multinível, teve por variável dependente o Ideb 2009 das escolas e variável independente os estudantes em situação de pobreza (BPBF), mas, para estudo multivariado, era necessário eleger outras variáveis independentes (2009). Em função do referencial teórico de análise já apresentado - fracasso escolar, pobreza e precarização da política educacional -, elegeram-se por variáveis independentes: PIB per capita, porte do município (população), custo-aluno e região. Assim, estruturou-se banco de dados a partir de quatro sistemas nacionais de informações: Censo Escolar/Inep, Ideb/Inep, Projeto Presença - MEC/Ministério do Desenvolvimento Social (MDS) e Instituto Brasileiro de Geografia e Estatísticas (IBGE). As variáveis tinham níveis diferentes, sendo que as do nível da escola eram Ideb e \%BPBF e as do nível do município: população, PIB per capita, custo-aluno e região. 
Para constituir o banco de dados, fez-se a opção por estudo do ensino fundamental, tendo em vista que a população BPBF tem condicionalidade educacional para o recebimento do benefício: todas as crianças e adolescentes entre 6 e 14 anos devem estar devidamente matriculados e com frequência escolar mensal mínima de $85 \%$ da carga horária. Essa faixa etária corresponde ao ensino fundamental.

Atualmente, o acompanhamento da frequência ocorre para quase 17 milhões de crianças e adolescentes que integram as famílias BPBF nos 5.563 municípios e no Distrito Federal. Na última coleta de 2010, do cadastro de beneficiários, enviado pelo MDS, que tinham identificação correta da situação escolar (15.178.704 crianças e adolescentes de 6 a 14 anos), o Projeto Presença obteve retorno da frequência escolar da ordem de $98,02 \%$. O foco desse programa é a família em situação de pobreza ou de extrema pobreza, e a exigência da frequência à escola das crianças e adolescentes caracteriza política pública que compreende a educação como um dos eixos de emancipação das famílias beneficiárias.

Para verificar se o fracasso escolar era instado na relação entre educação formal e população em situação de pobreza, utilizou-se o Ideb 2009 para a $4^{\mathrm{a}}$ série $/ 5^{\circ}$ ano. Como o banco de dados precisava permitir investigar objetivamente em que medida o fracasso escolar é instado na relação da educação formal com a população em situação de pobreza, optou-se por estudo que considerasse as informações disponibilizadas de todas as escolas brasileiras. Assim, adotou-se o Censo Educacional do Inep 2009 como base para a constituição do banco de dados. As informações de PIB per capita e população foram retiradas da pesquisa PIB dos Municípios 2004-2008, disponível no Sistema de Contas Nacionais do IBGE.

As opções relatadas definiram como elementos da pesquisa 31.660 escolas com Ideb (15\% das escolas brasileiras), 5.865.714 BPBF (37\% do universo de beneficiários) em 15.218.248 matrículas em 2009 (50\% do universo). A partir desses dados, calculou-se a correlação entre pobreza por meio do programa Statistical Package for Social Sciences (SPSS), identificada entre variável dependente Ideb e população em situação de pobreza - BPBF. Verificou-se que as grandezas trabalhadas eram muito diferentes, com Ideb variando de 0,7 a 8,6; PIB per capita, de $\mathrm{R} \$ 1.212,68$ a R\$ 239.505,56; e população municipal, de 1.039 a 11.016 .703 habitantes. Assim, tendo como objetivo a utilização de uma métrica comum, os valores foram transformados em escores z - unidades de desvio padrão - como recomendado por Hair et al. (2005).

\section{Algumas análises dos primeiros achados}

Uma primeira constatação: verificou-se que os BPBF constituíam 37\% das matrículas nessas escolas. Em função da anormalidade dos dados referentes à população das unidades da Federação, PIB per capita e população em situação de pobreza (\%BPBF), foi feita a opção pela correlação de Spearman (Tabela 1): 
Tabela 1 - Correlação de Spearman entre Ideb, PIB, População e Custo-Aluno, referentes ao Sub-Banco de Dados do Nível da Escola com Dados - 2009

\begin{tabular}{|l|c|}
\hline \multicolumn{1}{|c|}{ Variável } & $\begin{array}{c}\text { Ideb } \\
\mathbf{2 0 0 9}\end{array}$ \\
\hline \%BPBF & $-0,54$ \\
\hline População & 0,08 \\
\hline PIB p/c 2009 & 0,45 \\
\hline CA 2009 & 0,54 \\
\hline
\end{tabular}

Fonte: Elaboração própria

Notas: Ideb 2009 = Índice de Desenvolvimento da Educação Básica 2009.

\%BPBF $=$ Percentual de alunos beneficiários do Programa Bolsa Família

População $=$ Referente ao município onde se encontra a escola.

PIB p/c 2009 = PIB per capita do município onde se encontra a escola.

CA 2009 = Custo-aluno do Fundeb para o Estado onde se encontra a escola.

Os cálculos demonstraram correlação: forte e negativa entre pobreza (percentual de BPBF) e Ideb $(r=-0,54)$; irrelevante entre Ideb e porte do município $(r=0,08)$; forte e positiva entre Ideb e PIB per capita $(r=0,45)$; e igualmente alta entre Ideb e custo-aluno $(r=0,54)$. Assim, uma primeira leitura permite identificar que o Ideb está associado à presença da população em situação de pobreza, ao PIB per capita e ao custo-aluno do Fundo de Manutenção e Desenvolvimento da Educação Básica e de Valorização dos Profissionais da Educação (Fundeb), com taxas de correlação consideradas extremamente fortes para fenômeno social (Hair et al., 2005).

Constatada a adequação das variáveis, foi realizado o estudo multinível entre a variável dependente Ideb 2009 e as variáveis de controle para composição do modelo ideal do percentual de alunos em situação de pobreza, PIB per capita, porte do município e custo-aluno. Seguindo uma tradição nos estudos nacionais, optou-se por reconhecer as regiões como variável de contexto. Uma primeira escolha era transformá-las em variáveis Dummys, entretanto, tendo em vista a diferença de Ideb das regiões - Norte (N) e Nordeste (NE) com os índices mais baixos e Sul (S), Sudeste (SE) e Centro-Oeste (CO) com índices mais altos -, optou-se pela eleição de variável de contexto binária (0 e 1), em que N e NE foram agrupadas na Região 0 e S, SE e CO na Região 1. Finalmente, no que se refere aos níveis, as variáveis explicativas para o primeiro nível (escola) foram o Ideb e o percentual de população em situação de pobreza (BPBF) e para o segundo nível (município), porte do município - definido pela população municipal (POP), PIB per capita, custo-aluno do Fundeb e região.

Foram testadas todas as variáveis apresentadas, mas estranhamente a variável PIB per capita foi excluída do modelo final do estudo escola/ município por apresentar razão crítica (teste t) inferior a 1,96. Esse efeito foi entendido como evidência importante e será discutido mais a frente na análise dos resultados. 
Para que o intercepto pudesse ser interpretado, as variáveis cujo valor 0 não fizesse sentido foram centralizadas pela média. Utilizou-se o software MlWin, versão 2.2, e o método de estimação Interative Generalised Least Squares - IGLS (Rasbash et al., 2005). Para a elaboração dos modelos, empregaram-se os cinco passos propostos por Hox (2002) e adaptados por Andrade e Laros (2007), descritos a seguir.

No Modelo 1, dito modelo somente com intercepto ou vazio, foram inseridos apenas a variável dependente (Ideb) e o intercepto, sem nenhuma variável explicativa. Esse modelo (Tabela 2) proporciona uma estimativa de correlação intraclasse e também oferece uma medida de deviance (-2log máxima verossimilhança), a qual afere o desajuste dele devendo ser utilizada para comparar os diferentes modelos após a inserção de outras variáveis.

Tabela 2 - Modelo 1 (Vazio) sem Variáveis Explicativas Inseridas

\begin{tabular}{|c|c|c|c|}
\hline Variáveis Explicativas & \multicolumn{3}{|c|}{ Modelo 1} \\
\hline Efeito Fixo & Efeito & E.P. $(\gamma)$ & Razão t \\
\hline$\left(\gamma_{00}\right)$ Intercepto & $-0,01$ & 0,01 & - \\
\hline Efeito Randômico - Nível 2 & $\sigma_{\mathrm{u} 0}^{2}$ & E.P. $\left(\tau^{2}\right)$ & Razão-t \\
\hline$\left(\sigma_{\text {u0 }}^{2}\right)$ Variância intercepto & 0,69 & 0,01 & 69 \\
\hline Efeito Randômico - Nível 1 & $\sigma_{e}^{2}$ & E.P. $\left(\sigma_{\mathrm{e}}^{2}\right)$ & Razão-t \\
\hline$\left(\sigma_{\mathrm{e}}^{2}\right)$ Variância de $\left(\mathrm{R}_{\mathrm{ij}}\right)$ & 0,36 & 0,01 & 36 \\
\hline Correlação intraclasse (ICC) & 0,65 & & \\
\hline Deviance (gl) & 74333 (3) & & \\
\hline
\end{tabular}

Notas: Nível 2 = Município; Nível 1 = Escola; E.P. = Erro Padrão; Razão t = Efeito/EP. Deviance $=-2 \log$ máxima verossimilhança do modelo.

gl = graus de liberdade (parâmetros estimados)

Esse modelo serve para estipular dois valores que serão sempre comparados para verificação do desajuste dele e da variância intraclasse. Assim, o valor de referência calculado para intercepto foi aferido como -0,01, o deviance como 74.333 e a variância do nível 2 como 0,69 e a do nível 1 como 0,36. À medida que foram inseridas novas variáveis preditoras, o valor de deviance e da variância dos dados por nível e a correlação intraclasse calculada a partir das variâncias dos diferentes níveis precisam, necessariamente, diminuir.

Seguindo os passos recomendados por Andrade e Laros (2007), no Modelo 2 foi inserida a variável independente/preditora do nível da escola: população em situação de pobreza (\%BPBF). A partir desse modelo, também foi possível realizar o teste de qui-quadrado para as diferenças de deviance entre os modelos, bem como a variância explicada nos diversos níveis. Ao inserir a variável do nível 1 - \%BPBF, o deviance e a variância diminuíram; isso informa que a pobreza é variável com força explicativa do Ideb e que o modelo está ficando mais ajustado. Tais resultados são os disponibilizados na Tabela 3. 


\section{Tabela 3 - Modelo 2 com a Variável da Escola \%BPBF}

\begin{tabular}{|c|c|c|c|}
\hline Variáveis Explicativas & \multicolumn{3}{|c|}{ Modelo 2} \\
\hline Efeito Fixo & Efeito & E.P. $(\gamma)$ & Razão t \\
\hline Intercepto & 0,07 & 0,01 & - \\
\hline (Nível 1) \%BPBF & $-0,42$ & 0,01 & -42 \\
\hline Efeito Randômico - Nível 2 & $\sigma_{v 0}^{2}$ & E.P. $\left(\tau^{2}\right)$ & Razão t \\
\hline$\left(\sigma_{v 0}^{2}\right)$ Variância & 0,46 & 0,01 & 46 \\
\hline Efeito Randômico - Nível 1 & $\sigma^{2}$ & E.P. $\left(\sigma^{2}\right)$ & Razão t \\
\hline$\left(\sigma^{2}{ }_{e}\right)$ Variância & 0,32 & 0,01 & 32 \\
\hline Correlação intraclasse (ICC) & 0,59 & & \\
\hline Deviance (gl) & $68254(4)$ & & \\
\hline$\Delta$ Deviance $(\Delta \mathrm{gl})$ & $6079(1)$ & & \\
\hline Razão crítica de $\Delta$ Deviance & 6079 & & \\
\hline Variância explicada do nível 1 & $11 \%$ & & \\
\hline Variância explicada do nível 2 & $33 \%$ & & \\
\hline
\end{tabular}

Notas: Nível 1 = Escola; Nível 2 = Município.

$\%$ BPBF $=$ Percentual de alunos beneficiários do Programa Bolsa Família

E.P. = Erro Padrão; Razão t $=$ Efeito/EP; Deviance $=-2 \log$ máxima verossimilhança do modelo; $\mathrm{gl}=$ graus de liberdade (parâmetros estimados); $\Delta$ Deviance $=$ Diferença de -2 log Máxima verossimilhança entre os modelos 1 e 2; $\Delta \mathrm{gl}=$ Diferença entre graus de liberdade dos modelos 1 e 2; Razão crítica de $\Delta$ Deviance $=\Delta$ Deviance $/ \Delta \mathrm{gl}$.

Para o cálculo da variância explicada, considerou-se os modelos 1 e 2 .

Conforme já informado, "o pesquisador procura é que, a cada passo, o deviance seja menor" (Puente-Palacios; Borges-Andrade, 2005, p. 69). Foi o resultado encontrado: o Modelo 1 - Vazio - teve deviance de 74.333 e o Modelo 2 - com \%BPBF - teve deviance de 68.254. Outra medida fornecida foi a diminuição da variância do nível 1 (11\%) e do nível 2 (33\%), ou seja, a análise dos resultados nos informa que o modelo está mais adequado. Outro ponto a ser destacado: surpreende a magnitude do efeito negativo do \%BPBF no Ideb $(-0,42)$.

No Modelo 3, além das variáveis explicativas do primeiro nível (\%BPBF), foram inseridas de maneira fixa as variáveis explicativas do segundo nível (população, custo-aluno Fundeb e região). Em ambos os modelos, conforme já citado, os coeficientes de regressão das variáveis explicativas são mantidos fixos, assumindo-se que apenas o intercepto varia entre os municípios. Esses dados podem ser confirmados na Tabela 4.

A Tabela 4 nos informa que os efeitos calculados para as escolas, sem efeito randômico ou de interação, foram: \%BPBF $\mathrm{r}=-0,29$; custo-aluno $r=0,11$; população $r=-0,11$; e região $r=0,90$, ou seja, há impacto da pobreza no Ideb da escola, entretanto, varia conforme a região. O porte do município tem impacto negativo no Ideb (menores municípios têm escolas com maiores índices) e o custo-aluno tem impacto positivo, podendo ser analisado como efeito de moderação da pobreza. 
Tabela 4 - Modelo 3 com as Variáveis Explicativas do Nível 1 e 2

\begin{tabular}{|c|c|c|c|}
\hline \multirow{2}{*}{$\begin{array}{l}\text { Variáveis Explicativas } \\
\text { Efeito Fixo }\end{array}$} & \multicolumn{3}{|c|}{ Modelo 3} \\
\hline & Efeito & E.P. $(\gamma)$ & Razão t \\
\hline Intercepto & $-0,57$ & 0,01 & - \\
\hline (Nível 1) \%BPBF & $-0,29$ & 0,01 & -29 \\
\hline (Nível 2) Custo-aluno & 0,11 & 0,01 & 11 \\
\hline (Nível 2) População & $-0,11$ & 0,01 & -11 \\
\hline (Nível 2) Região & 0,90 & 0,02 & 45 \\
\hline Efeito Randômico - Nível 2 & $\sigma_{v 0}^{2}$ & E.P. $\left(\tau^{2}\right)$ & Razão $\mathrm{t}$ \\
\hline$\left(\sigma_{v 0}^{2}\right)$ Variância & 0,26 & 0,01 & 26 \\
\hline Efeito Randômico - Nível 1 & $\sigma_{\mathrm{e}}^{2}$ & E.P. $\left(\sigma_{\mathrm{e}}^{2}\right)$ & Razão t \\
\hline$\left(\sigma_{\mathrm{e}}^{2}\right)$ Variância & 0,32 & 0,01 & 32 \\
\hline Correlação intraclasse (ICC) & \multicolumn{3}{|l|}{0,45} \\
\hline Deviance (gl) & \multicolumn{3}{|l|}{$63778(7)$} \\
\hline$\Delta$ Deviance $(\Delta \mathrm{gl})$ & \multicolumn{3}{|l|}{$4476(3)$} \\
\hline Razão crítica de $\Delta$ Deviance & \multicolumn{3}{|l|}{1492} \\
\hline Variância explicada do nível 1 & \multicolumn{3}{|l|}{$11 \%$} \\
\hline Variância explicada do nível 2 & \multicolumn{3}{|l|}{$62 \%$} \\
\hline
\end{tabular}

Notas: As variáveis foram inseridas na ordem que consta nesta tabela.

Nível 1 = Escola; Nível 2 = Município.

$\%$ BPBF $=$ Percentual de alunos beneficiários do Programa Bolsa Família.

Região = Codificada em 0 para as Regiões Norte (N) e Nordeste (NE) e 1 para as Regiões Sul (S), Sudeste (SE) e Centro-Oeste (CO).

E.P. = Erro Padrão; Razão t $=$ Efeito/EP; Deviance $=-2$ log máxima verossimilhança do modelo; gl = graus de liberdade (parâmetros estimados); $\Delta$ Deviance $=$ Diferença de -2 log Máxima verossimilhança entre os modelos 2 e 3; $\Delta \mathrm{gl}=$ Diferença entre graus de liberdade dos modelos 2 e 3; Razão crítica de $\Delta$ Deviance $=\Delta$ Deviance $/ \Delta \mathrm{gl}$.

Para o cálculo da variância explicada, considerou-se os modelos 1 e 3 .

No Modelo 4, também denominado de modelo de coeficientes randômicos, avalia-se se os coeficientes de regressão (Betas) das variáveis explicativas têm um componente significativamente diferente de zero entre os municípios, ou seja, se podem ser randômicos. Essa investigação busca verificar se a variância de inclinação do impacto da população em situação de pobreza muda de escola para escola. O Modelo 4 nos diz que sim. É importante destacar esse achado - mesmo que seja apenas para reforçar que estudamos um fenômeno social e que não há um efeito fixo, regular: o impacto da população em situação de pobreza no Ideb é inconteste, entretanto, não é o mesmo em todas as escolas, pois há elementos da organização do trabalho pedagógico que modulam esse impacto, e depende também do município, do Estado e da região. É o apresentado na Tabela 5. 
Tabela 5 - Modelo 4 com Coeficientes Randômicos

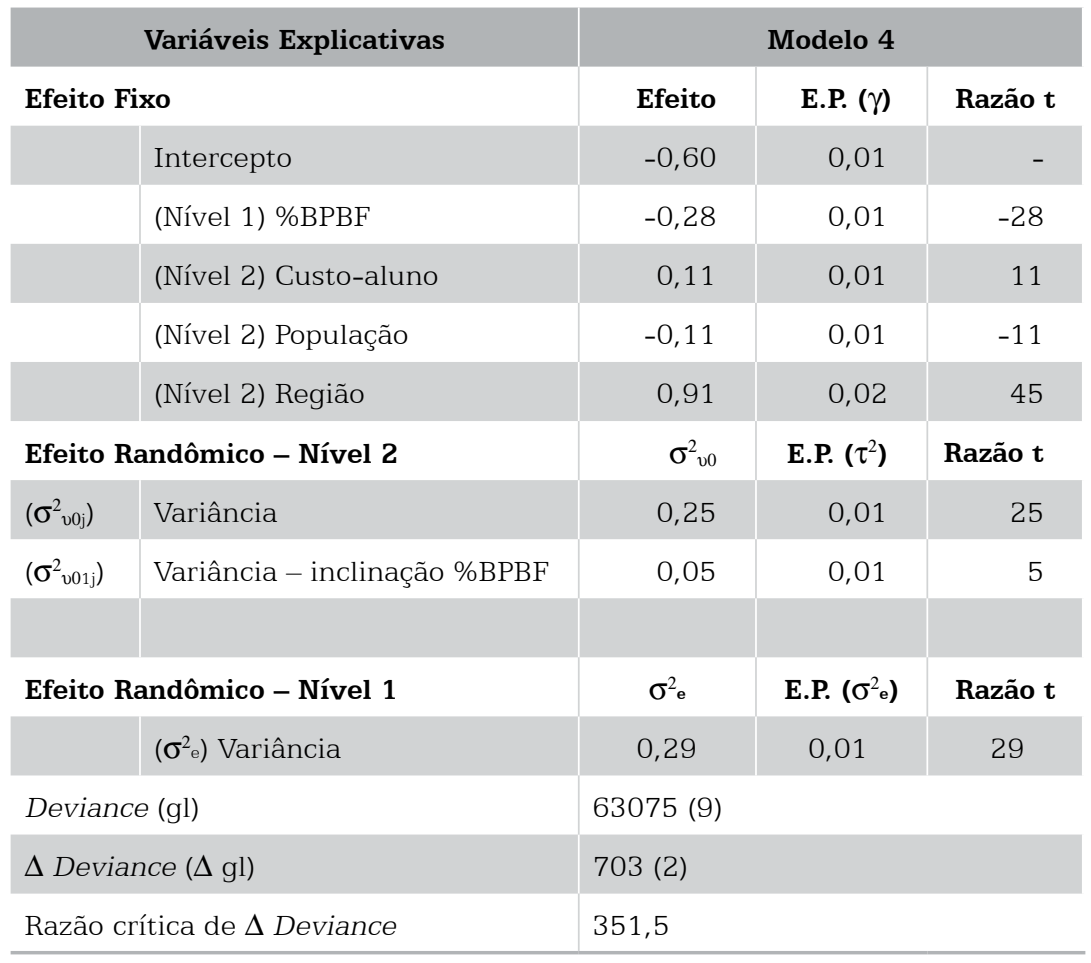

Notas: As variáveis foram inseridas na ordem que consta nesta tabela.

Nível 1 = Escola; Nível 2 = Município.

$\% \mathrm{BPBF}=$ percentual de alunos beneficiários do Programa Bolsa Família.

Região = Codificada em 0 para as Regiões Norte (N) e Nordeste (NE) e 1 para as Regiões Sul (S), Sudeste (SE) e Centro-Oeste (CO).

E.P. = Erro Padrão; Razão t $=$ Efeito/EP; Deviance $=-2$ log máxima verossimilhança do modelo; $\mathrm{gl}=$ graus de liberdade (parâmetros estimados); $\Delta$ Deviance $=$ Diferença de -2 log Máxima verossimilhança entre os modelos 3 e $4 ; \Delta$ gl $=$ Diferença entre graus de liberdade entre os modelos 3 e 4; Razão crítica de $\Delta$ Deviance $=\Delta$ Deviance $\Delta \mathrm{gl}$

O próximo passo foi tentar explicar a randomização encontrada no modelo anterior. Era preciso descobrir, entre as variáveis preditoras, que interações explicariam melhor a randomicidade do impacto no Ideb, ou seja, buscar entender a relatividade da randomização encontrada entre as variáveis explicativas de primeiro e segundo nível. Por meio do cálculo das interações entre custo-aluno e \%BPBF e também da interação entre região e \%BPBF, buscou-se verificar a interferência dessas interações no impacto da população em situação de pobreza sobre o Ideb da Escola. Os resultados são elucidativos: tanto custo-aluno como região modulam/ interferem no impacto da pobreza no Ideb. Para Hair et al. (2005, p. 133), o efeito de moderação ocorre quando uma "variável independente (a variável moderadora) faz com que a relação entre um par de variáveis dependente/independente mude". No Modelo 5, a variável binária região modera/altera o impacto da pobreza no Ideb, assim como a variável custoaluno, ou seja, o impacto da pobreza é maior ou menor dependendo da região e diminui pelo custo-aluno. 


\section{Considerações finais}

Os resultados do estudo multinível permitiram comprovar a hipótese formulada: a relação da política social de educação com a população em situação de pobreza se manifesta, consideravelmente, por meio do fracasso escolar. O impacto negativo da pobreza no Ideb foi confirmado no estudo regressivo e multinível, que visibilizou outras questões também importantes a serem destacadas.

A pesquisa ainda evidenciou o imenso quantitativo de pobres nas escolas públicas do Brasil que não são considerados nem por essas instituições nem pelas políticas educacionais. Em nossa análise, a partir de Freitas $(2002,2007)$, essa invisibilidade nos leva a reprodutividade no sistema educacional público, em que a população em situação de pobreza, por ser negligenciada - e até mesmo discriminada - pela política educacional, acaba impactando negativamente o Ideb da escola. Há invisibilidade da pobreza. O cotidiano escolar e a maneira com que as políticas educacionais orientam o funcionamento das escolas vêm "cegando socialmente" essa instituição, impedindo que a pobreza seja descoberta e que sua presença acione sensibilidade, respeito, consideração e solidariedade. Os pobres continuam sem ter com quem contar, à margem, mesmo estando presente. É imperioso apor visibilidade à pobreza presente na escola pública.

A invisibilidade também é um conceito que ajuda a entender a desresponsabilização da escola com as classes populares. Invisibilidade elaborado por Boaventura Santos (2001) e aprofundado por Costa (2004, 2011) - pode ser definida como a negação social, pois diante de alguns grupos aciona-se uma política de invisibilidade que distorce e cega ante a realidade. Esse conceito é muito utilizado na literatura sobre raça e etnia, mas também é adequado à questão de classe. Somente por meio da invisibilidade dos pobres, a escola pode adotar práticas que os rotulam e estigmatizam como "indisciplinados", "lentos", "defasados", "atrasados", e a pobreza é transformada em atributos e impressões que coisificam o aluno (e sua família) desse estrato.

Hoje, luta-se pela implementação de uma política de visibilidade do negro, do índio, como instrumento legal complementar e necessário à garantia do direito à educação, capaz de requalificá-la. O mesmo deve ser feito em relação à população em situação de pobreza presente na escola pública.

A desigualdade da qualidade educacional entre escolas fere o caráter democrático e universal da educação pública brasileira determinada na Constituição Federal. Análises mais cuidadosas sobre os indicadores educacionais disponíveis permitem constatar esse (forte) impacto da condição econômica na situação de fracasso escolar, de modo que os baixos indicadores nos dirigem, quase sempre, aos mesmos lugares dos de vulnerabilidade social e pobreza.

A despeito das informações oficiais que afirmam que 28 milhões de brasileiros saíram da pobreza nos últimos oito anos, 36 milhões 
alcançaram a classe média e a população em situação de extrema pobreza totaliza apenas 16,27 milhões de pessoas (8,5\% da população total), no que se refere à população escolar, o contingente de pobres continua muito grande: representa quase metade das crianças e adolescentes de até 14 anos do ensino fundamental. Do total de matrículas na educação fundamental pública, 44\% dos alunos estão em situação de pobreza e miséria. Divididos por sistema de ensino, os números são ainda mais alarmantes: entre seus alunos, o sistema estadual apresenta 41\% de BPBF e o sistema municipal, 55\%. Essas informações precisam ser alardeadas para que sejam consideradas na formulação de ações, programas e políticas públicas que pretendam enfrentar a situação de pobreza na área educacional, social ou econômica. Entretanto, infelizmente, não há uma única ação voltada para esse público no Plano Brasil Sem Miséria ou no Plano Plurianual 2008-2011 (PPA).

Como o impacto da variável independente porte do município não teve influência positiva sobre o Ideb (ao contrário), ressalta-se aqui a necessidade de estudos mais aprofundados sobre esse dado. Contudo, optou-se por lembrar que esse resultado pode ser indício de ausência de intersetorialidade nas políticas sociais - os maiores índices são de escolas e sistemas municipais de pequeno porte. Para Sposati (2007), intersetorialidade requer o reconhecimento de que toda a política social precisa se articular para pretender responder à múltipla realidade socioeconômica dos cidadãos. Entretanto, os resultados do estudo estatístico apresentado foram compreendidos como mais uma evidência da complexidade socioeconômica dos municípios de grande porte que, em função da desigualdade e de sua dinâmica socioeconômica, especialmente em razão da desproteção social tributária da ausência do Estado, imprimem às camadas populares vulnerabilidades e condições de vida inaceitáveis para a riqueza que encerram.

A triste constatação de que o PIB per capita não adentra a escola pode ser interpretada como fruto de um truncado e inadequado pacto federativo na temática tributária (Salvador, 2010). A política tributária não tem permitido que a riqueza gerada socialmente alcance a escola e beneficie mais democraticamente a população. Entretanto, a pobreza chega a escola de forma inconteste, restando a essa instituição buscar reverter a situação de risco e vulnerabilidade de forma isolada, sem muitas condições objetivas para tanto.

A saída para essa distorção tributária parece estar na elevação do custo-aluno - pela capacidade que apresentou em moderar e mediar a pobreza nas escolas. A defesa de Carreira e Pinto (2007) precisa ser considerada como agenda em tempos de aprovação do Plano Nacional de Educação 2011-2020 (PNE). É necessário assegurar o Custo-AlunoQualidade (CAQ) no texto da lei, com reivindicação de pelo menos 10\% do PIB para financiamento da educação. Somente assim pode-se efetivamente enfrentar a reprodutividade encontrada nas escolas e sistemas de ensino público. 
Apontar desafios e fragilidades da política educacional deve seguir a linha de corroborar para a existência de uma escola justa, que ainda não existe, mas que deve ter a força de um futuro cada vez mais próximo. É fundamental termos a igualdade como condição possível para transformar o presente e eleger o território escolar como locus privilegiado para o enfrentamento das vulnerabilidades sociais de grande parte das crianças e adolescentes que frequentam a escola, por meio de ampliação em seu financiamento e de políticas intersetoriais à educação.

A qualidade da educação é multidimensional - assim como o fracasso escolar. De um modo geral, há consenso na formulação de políticas públicas de que a qualidade educacional envolve, necessariamente, valorização dos profissionais da educação (inclusive, dos não docentes) e investimento em tecnologia educacional e infraestrutura e em qualidade e procedência dos conteúdos. Nesse sentido, não é a luta apenas de um dos atores dessa política que poderá transformar a instituição escolar. É necessário intervir em todo o ciclo de políticas públicas educacionais.

A despeito da realidade reprodutivista que este trabalho aponta, não se enxerga a escola negativamente, muito pelo contrário, é uma das instituições mais importantes para o atual estágio civilizatório, tanto para a sociedade como para o sujeito, pois auxilia na socialização crítica e na proteção e garantia dos direitos dos alunos, especialmente dos mais pobres. Critica-se sua parcialidade e reprodutividade, atribuída aqui muito mais ao financiamento restritivo, a precarização do espaço-tempo escolar e a políticas de invisibilidades do que à essência da instituição escolar. Entretanto, a realidade constatada não é única, posto que "o importante é não reduzir o realismo ao que existe, pois, de outro modo, podemos ficar obrigados a justificar o que existe, por mais injusto ou opressivo que seja" (Santos, 2001, p. 29).

\section{Referências bibliográficas}

ALGEBAILE, E. Escola pública e pobreza no Brasil: a ampliação para menos. Rio de Janeiro: Lamparina, 2009.

ANDRADE, J. M.; LAROS, J. A. Fatores associados ao desempenho escolar: estudo multinível com dados do SAEB/2001. Psicologia: Teoria e Pesquisa, Brasília, v. 23, n. 1, p. 33-41, jan./mar. 2007. Disponível em: <http://www.scielo.br/pdf/ptp/v23n1/a05v23n1.pdf>. Acesso em: set. 2011.

ARRETCHE, M. Federalism and territorial equality: a contradiction in terms? Dados, Rio de Janeiro, v. 5, Selected Edition, 2010 . Disponível em: <http://socialsciences.scielo.org/scielo. php?script=sci arttext\&pid=S0011-52582010000100002\&lng=pt\&nrm=iso $>$. 
BARBOSA, M. L. de O. Desigualdade e desempenho: uma introdução à sociologia da escola brasileira. Belo Horizonte, MG: Argvmentvm, 2010.

BOURDIEU, P. E; PASSERON, J. C. A reprodução: elementos para uma teoria do sistema de ensino. Rio de Janeiro: Francisco Alves, 1973.

BRASIL. Instituto Nacional de Estudos e Pesquisas Educacionais Anísio Teixeira (Inep). SAEB 2001: novas perspectivas. Brasília, 2001 a.

BRASIL. Instituto Nacional de Estudos e Pesquisas Educacionais Anísio Teixeira (Inep). SAEB: relatório nacional 2001. Brasília, 2001b.

BRASIL. Ministério da Educação (MEC). Plano de desenvolvimento da Educação: razões, princípios e programas. Brasília, 2007.

CARREIRA, D.; PINTO, J. M. R. Custo-aluno qualidade inicial: rumo à educação pública de qualidade no Brasil. São Paulo: Cortez, 2007.

COSTA, F. B. Homens invisíveis: relatos de uma humilhação social. São Paulo: Globo, 2004.

COSTA, F. B. Moisés e Nilce: retratos biográficos de dois garis: um estudo de psicologia social a partir de observação participante e entrevistas. 2008. 403 f. Tese (Doutorado em Psicologia) - Universidade de São Paulo, 2008.

CURY, C. R. J. Estado e políticas de financiamento em educação. Educação \& Sociedade, Campinas, v. 28, n. 100 Especial, p. 831-855, maio/ago. 2007. Disponível em <http://www.cedes.unicamp.br>.

DAIN, S. Financiamento público na perspectiva da política social. Economia e Sociedade, Campinas, v. 10, n. 2 (17), p. 113-140, 2001.

DALlARI, D. A. Elementos de Teoria Geral do Estado. 19. ed. São Paulo: Saraiva, 1995.

DUBET, F. As desigualdades multiplicadas. Revista Brasileira de Educação, n. 17, p. 5-19, maio/ago. 2001. Disponível em: < http://www. anped.org.br/rbe/rbedigital/RBDE17/RBDE17_03_FRANCOIS_DUBET. pdf $>$.

DUBET, F. O que é uma escola justa? Cadernos de Pesquisa, v. 34, n. 123, p. 539-555, set./dez. 2004.

DUBET, F. Democratização escolar e justiça da escola. Educação, Santa Maria, v. 33, n. 3, p. 381-393, set./dez. 2008. Disponível em: <http:// www.redalyc.org/articulo.oa?id=117117076002>. 
FREITAS, L. C. Crítica da organização do trabalho pedagógico e da didática. Campinas, SP: Papirus, 1995.

FREITAS, L. C. A internalização da exclusão. Educação \& Sociedade, Campinas, SP, v. 23, n. 80, p. 299-325, 2002.

FREITAS, L. C. Eliminação adiada: o ocaso das classes populares no interior da escola e a ocultação da (má) qualidade do ensino. Educação \& Sociedade, Campinas, SP, v. 28, n. 100 Especial, p. 965-987, out. 2007. Disponível em: <http://www.cedes.unicamp.br>.

FREITAS, L. C. et al. Avaliação educacional: caminhando pela contramão. 3. ed. Petrópolis, RJ: Vozes, 2011.

GUIMARÃES-IOSIF, R. M. Educação, pobreza e desigualdade no Brasil: impedimentos para a cidadania global emancipada. Brasília: Liber Livro, 2009.

HAIR, J. F. et al. Análise multivariada de dados. Porto Alegre: Bookman, 2005.

HENRIQUES, R. Desigualdade e pobreza no Brasil. Brasília: IPEA, 2000.

HENRIQUES, R. Raça e gênero nos sistemas de ensino. Brasília: UNESCO, 2002.

HOX, J. Multilevel analysis: techniques and applications. Mahwah: Lawrence Erlbaum Associates, 2002.

INSTITUTO DE PESQUISA ECONÔMICA APLICADA (Ipea). O impacto da infra-estrutura escolar na taxa de distorção idade-série das escolas brasileiras de ensino fundamental: 1998 a 2005. Rio de Janeiro, 2008. (Texto para Discussão, 1.338). Disponível em: <http://www.ipea.gov. br/agencia/images/stories/PDFs/TDs/td_1338.pdf>. Acesso em: 10 nov. 2010 .

LAROS, J. A.; MARCIANO, J. L. Análise multinível aplicada aos dados do NELS:88. Estudos em Avaliação Educacional, São Paulo, v. 19, n. 40, p. 263-278, maio/ago. 2008.

LAVINAS, L. Pobreza e exclusão: traduções regionais de duas categorias da prática. Revista Econômica, Niterói, v. 4, n. 1, 2002. Disponível em: $<$ http://www.uff.br/revistaeconomica/v4n1/lavinas.pdf > . Acesso em: fev. 2010.

MARTINS, P. S. FUNDEB, federalismo e regime de colaboração. Campinas: Autores Associados, 2011. 
MARX, K.; ENGELS, F. A ideologia alemã. 4. ed. São Paulo: Martin Claret, 2005.

MARX, K. Teses contra Feuerbach. São Paulo: Abril Cultural. 1979. (Os Pensadores)

PATTO, M. H. S. A reprodução do fracasso escolar. São Paulo: T. A. Queiroz, 1990.

PEREGRINO, M. Trajetórias desiguais: um estudo sobre os processos de escolarização pública de jovens pobres. Rio de Janeiro: Garamons, 2010.

PEREIRA, P. A. P. Perspectivas teóricas sobre a questão social no Serviço Social. Temporalis: revista da Associação Brasileira de Ensino e Pesquisa em Serviço Social (ABEPSS), Porto Alegre, v. 7, p. 112-122, 2003.

PRADO, S. Transferências fiscais no Brasil: o lado "esquecido" da reforma tributária. In: PINTO, M.; BIASOTO JR., G. Política fiscal e desenvolvimento no Brasil. Campinas: Ed. da Unicamp, 2006. p. 173236.

PUENTE-PALACIOS, K. E.; BORGES-ANDRADE, J.E. O efeito da interdependência na satisfação de equipes de trabalho: um estudo multinível. Revista de Administração Contemporânea [online]. Curitiba, v. 9, n. 3, p. 57-78, 2005. Disponível em: < http://dx.doi.org/10.1590/ S1415-65552005000300004>.

PUENTE-PALACIOS, K. E.; LAROS, J. A. Análise multinível: contribuições para estudos sobre efeito do contexto social no comportamento individual. Estudos de Psicologia, Campinas, v. 26, n. 3, set. 2009. Disponível em: <http://www.scielo.br/scielo.php?script=sci_ arttext\&pid=S0103-166X2009000300008\&lng=en\&nrm=iso $>$.

Acesso em: 18 dez. 2011.

RASBASH, J. et al. A User's Guide to MLwiN v. 2.0. London: Centre for Multilevel Modelling, University of Bristol, 2005.

SALVADOR, E. Fundo público e seguridade social no Brasil. São Paulo: Cortez, 2010.

SANTOS, Boaventura de Souza. Para uma concepção multicultural de direitos humanos. Contexto Internacional, Rio de Janeiro, v. 23, n. 1, p. 7-34, 2001.

SOARES, Kelma J. A política social de educação e a política social de assistência social: debate sobre transferência de renda e educação. 
In: SEMINÁRIO DE POLÍTICA NO MERCOSUL, 3., 2011, Pelotas. Anais:temas emergentes e perspectivas para o futuro. Pelotas, RS, 2011. Disponível em: < http://www.tedis.unb.br/images/stories/ ProducoesTEDis/kelma_artigopelotasucpel2011.pdf > .

SOUZA, J. A construção social da subcidadania: para uma sociologia política da modernidade periférica. Belo Horizonte: UFMG; Rio de Janeiro: IUPERJ, 2003.

SPOSATI, A. Assistência social: de ação individual a direito social. Revista Brasileira de Direito Constitucional, n. 10, jul./dez. 2007. Disponível em: <http://www.esdc.com.br/RBDC/RBDC-10/RBDC-10435-Aldaiza_Sposati.pdf $>$.

VILLAS BOAS, B. M. de Freitas. É proibido repetir, mas é obrigatório aprender. In: - Virando a escola do avesso por meio da avaliação. São Paulo: Papirus, 2008.

Natália de Souza Duarte, doutora em Política Social pela Universidade de Brasília (UnB), é assessora especial da Secretaria de Educação do Distrito Federal (SEDF) e professora do Centro Universitário do Distrito Federal (UDF), Brasília, Distrito Federal, Brasil.

nataliasduarte@gmail.com

Recebido em 31 de agosto de 2012.

Aprovado em $1^{\circ}$ de março de 2013. 